\title{
The inclusive educational experience of exceptional and normal children in primary school for architectural design
}

\author{
Pastraporn Thipayasothorn ${ }^{1,}{ }^{*}$, Gasamapong Pongchomporn ${ }^{2}$, Panida Jantaragant ${ }^{3}$, Jintana Nokyoo ${ }^{4}$ \\ 1, 2,3,4 King Mongkut's Institute of Technology Ladkrabang, Bangkok Thailand
}

\section{Keywords:}

learning environment

Inclusive education

School buildings

Exceptional and normal children

Received: 27 Feburary 2016

Accepted: 30 April 2016

Published: 12 August 2016

\begin{abstract}
The study of the inclusive educational environment of exceptional and normal children in primary school for architectural design aimed to establish guidelines for creating an environment for inclusive education. Building utilization of thirty-five elementary schools providing the inclusive educational program in Bangkok was analyzed to study the following aspects: 1) The environment of exceptional and normal students' inclusive classes at the regional center for special education 2) The patterns of the environment suited to the exceptional and normal students' inclusive classes 3) Environmental management policies for the inclusive classes of exceptional and normal students. Information was gathered from surveys, observations, questionnaires, document analysis, interviews, and non-experimental research. The findings showed that the usable spaces in school buildings were designated to enhance the three kinds of social learning experience: 1) Support class control 2) Help developing students' personalities consisting of physical, verbal, and emotional expressions that are socially accepted 3) Recognition and learning, which are needed for the increase of learning experience, were caused by having an interaction with the environment. Thus, the school buildings' space designation positively affected the environmental management of exceptional and normal students' inclusive classes.
\end{abstract}

(C) 2016 The Author(s). Published by TAF Publishing.

\section{INTRODUCTION}

Thai government, nowadays, provides Thai people with a proper education covering from kindergarten to higher education by encouraging widespread opportunities to school age population in every region of Thailand. It is the duty of all educational organizations to comply with the policy of the national scheme of education 2002-2016. The intentions stated in the national scheme of education are: (1) Improve the qualities of life that means having excellent health, mind, and knowledge; moreover, having virtuous and ethical life that enables them to live happily with other people. (2) Develop Thai society to

\footnotetext{
*Corresponding author: Pastraporn Thipayasothorn

E-mail: pastraporn.th@kmitl.ac.th
} 
become stronger and fit for the three balances of a potential society that are wisdom and learning, as well as solidarity and generosity. Then, Thai society would become a developed social environment that is the basis of individual development. The educational organizations need to follow the policy by ensuring that the school age children, either normal or exceptional children, are included in the educational system as much as possible. Consequently, inclusive educational program of exceptional and normal children was established in order to encourage learning in normal environment for children with special needs or children with any kind of impairment. The program will consider the abilities of each child to enhance their learning opportunity that will consequently allow them to live happily in the society.

Building the capacity and capability in the learning-age children either for social development is considered as a fundamental of country's stability. This can proceed with education reform, learning process and learning support system for development of children with talents. Such policies create greater choice in education range from special educations school, school for specific purpose, inclusive school, parallel classroom, regular classroom, to education outside the school and other alternative educations as part of inclusive learning environment. The certain environment is a context of critical friendship formation, the important kind of social interaction. By peer interaction and observation, children will learn to adjust themselves, get to know themselves and others. Even young children will learn how to interact with friends. Hence, environmental management of inclusive classes played an important role in bringing children with special needs or disabled students to inclusive class along with other normal students (Waitoller et al., 2014, Yildiz, 2015).

The guideline of inclusive education management (Department of General Education Elementary and Adult Education Department, 1997) had discussed the importance of inclusive education for children with special needs. Educational reforms for people with disabilities need to be boosted and acquire cooperation from all government sectors. To increase opportunities and equality between exceptional and normal children, the inclusive education management should be supported to improve children's social interaction skills. From the requirements above, the development of the physical environment suited to the inclusive education for exceptional and normal children is important. In other words, physiological needs consist of school buildings, usable spaces, facilities, building layouts, including many activities that link school with surrounding communities.

\section{Objectives}

1. To study the school buildings' environment of the Inclusive education of exceptional and normal children at the regional centre for special education

2. To create a model of school buildings of the Inclusive education of exceptional and normal children suitable for each local area.

3. To set an environmental policy for environmental management of exceptional and normal students' inclusive education.

\section{LITERATURE REVIEW}

Related to school environmental management for the physical environment outside the buildings and green space management, Pilanthananin (1985) 
stated that the buildings having empty or open spaces are supposed to be designed with sufficient high ceiling. Moreover, the shape of this empty space either inside or outside the building might be formed into slightly different shapes such as a circle, half circle, pentagon, and even hexagon. In addition, ceilings with plain design seemed to be old and boring while ceilings with other styles would make them look more interesting. The empty space outside the school building was very important since it was not only used for recreational activities, but it was also a place for relaxing and social interaction. The open area could be more inviting if it was gardened and decorated properly because the green of grass and trees help decreasing stress of both students and teachers (Chanrungrueng, 1998). Thus, School and trees were meant to be together like in some northeastern school that the author had been to. Wild gardens planted at those schools indeed improved the school's appearance to be livelier.

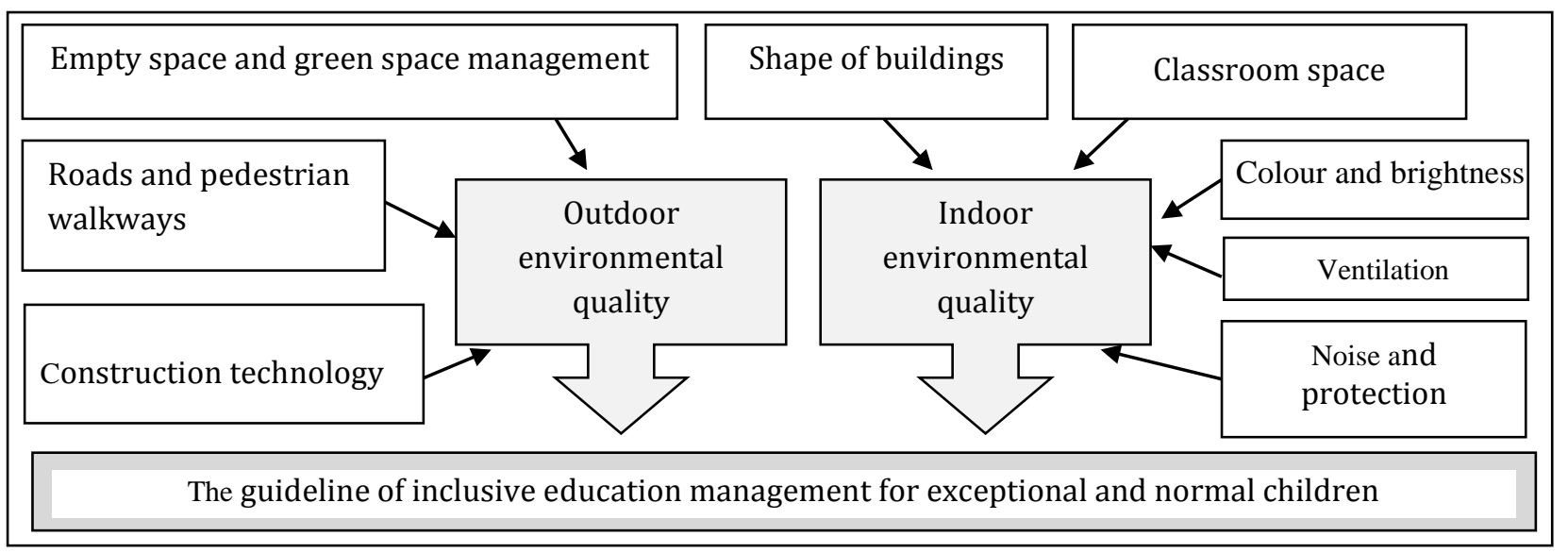

FIGURE 1. The concept of inclusive education environment

According to indoor environmental management, Srisuwan (1999) pointed that school buildings and environment within the school contribute to physical, mental, intellectual, and social development of students. The buildings and environment were not only a stable, residential building protecting people from rain and sun light, but also a meeting place for social interaction between teachers and students, including school administrators and local people. Generally, school buildings were, too, a center of educationist, materials for learning and teaching; besides, it was a center of many educational activities for students and the community as well (Pimolyanon, 2002). In addition, the buildings and the school environment also influenced behavior, attitude, values, intelligence, and social participation of students and teachers. The special education became more necessary as there were various methods to aid children with different types of special needs (Chumnui, 2004). For example, those children might be blind, deaf, hard of hearing, or have physical disabilities, mental retardation, and even brain damage. Moreover, their physical or mental development could be really slow and they might have problem with moods, learning or many other things.

The layout of educational area should be done carefully to eliminate obstacles that might occur. The edge, slope, width, and surface of the walking path are supposed to be fit for wheelchairs and canes as well as the installation of 
drinking water and light switches that should be reachable for students etc. (Techakitkajorn, 1997). Recommendations should be made of buildings designed to enable students to learn safely and comfortably as much as possible; thus, they should be applied to each group of students accordingly. Besides, good school buildings and environment could improve students' attitude toward learning and, in return, the students would bring pride and glory to themselves and even their institute. In the past, school buildings had a standard construction pattern that would specify shape, size, area, and functions thoroughly. In contrast, the current buildings must be designed to support future educational ideas and needs. Accordingly, the space ought to be flexible and suitable for human's highly reactive perception that expected to experience unusual, new things. The present shapes of buildings were changed from plain tall rectangular column into a circular and hexagonal building and other exciting shapes. On the other hand, the roof and the ceiling did not need to be flat. The structures could be designed to facilitate the control of light, sound and architectural styles.

In order to manage classroom for the inclusive education, there were two important components that should be taken into account. Those were classroom's environmental management and creating learning environment. Each component could be described as follows. 1) Arranging usable space for recreational activities that would enhance individual as well as large and small group learning. Therefore, the classroom should have a corner or center of activities; namely, quiet corner, test center, inclusive teaching, working corner for two children, and small-group working corner. Moreover, reference search and audio-visual education center, small group teaching, including student informational board and exhibition area were required as well. 2) The inclusive classroom that supported learning needed to provide reasonably large space for recreational and educational activities that enabled teacher to teach variously and continually.

The inclusive education of exceptional and normal children started from special education in particular school for children with impairments. This kind of education rather focused on self-help skills development than educational skills. Later, policy and special educational operation were based on the Constitution of the Kingdom of Thailand (Devahasdin De Ayutthaya, 1987), section 43 which stated that "Everyone shall have equal rights in receiving at least 12 years of education." Then, the National Education Act directed national education to be concerned with learning and proceed for the growth of individuals and society. In addition, knowledge derived from the environmental management in social learning and other supporting factors necessarily boosted lifelong knowledge of children, especially ones with special needs. According to section 10 of the Act, educational management should be done thoroughly and carefully by a person with rights and equal opportunity in the education, provided by government, for at least 12 years. Children with physical, mental or intellectual disabilities as well as children having problem with communication, social engagement, and learning would have full rights to receive basic education without any extra cost. Furthermore, reference Department of General Education Elementary and Adult Education Department (1997) stated that "the special education's objective was to provide proper education for children with physical, mental, and intellectual impairments so that they could 
develop their emotion and intelligence effectively. The inclusive education management for special children could start from pre-elementary school to university. This indicated that children with disabilities had more opportunity and the rights to participate in various kinds of school and in all levels of education, according to National Education Development Plan, 2008.

\section{RESEARCH METHODOLOGY}

In the research of inclusive educational environment of exceptional and normal children in primary school for architectural design, the researchers had studied and gathered all information through these following methods:

1. Designing research plan. It was non-experimental research that varied according to research variables which were:

\section{Population}

According to special education schools' data and information 2010, there were 1,124 people consisting of teachers/instructors, caretakers, and building attendants in all over thirty-five elementary schools at the regional centre for special education in Bangkok.

\section{Sampling}

In this study, the equation $\mathrm{n}=\mathrm{N} / 1+\mathrm{N}(0.05) 2$ was used to specify the number of samples. For 295 samples by probability sampling, every unit of population would have equal possibility to be sampled.

Research Tool. There were two research tools based on these following objectives:

Collecting quantitative data with methodical survey and observation. The researchers had collected information from thirty-five inclusive schools.

The survey and observation could be divided into two parts: 1 . Outdoor environment 2. Indoor environment.

Collecting quantitative data with methodical survey and observation from teachers/instructors, caretakers, and building attendants in all over thirty-five elementary schools had four parts that were: 1. General information of respondents 2. Awareness of inclusive education 3. Uses of Inclusive educational environment 4 . The inclusive education development.

Locations. Locations were 35 special education schools in Bangkok which consisted of Education service area office region 1), 2) and 3).

1) Education service area office region 1: Dipangkorn Wittayapat (Watbot) School, Prathom nonsee School, Phayathai School, Wat Chana Songkram School, Sommanas School Plabpla Chai School, Maha Veeranuwatr School, Tung Mahamek School, Samsen Primary School, Sai Nam Thip School, Darakarm School.

2) Education service area office region 2: Phibunwes Primary School, Uthaitaram School, Praya Prasert Suntrasai School, Bang Bua School, Maha Bud School, Ban Nong Born School, Pibool Uppatham School, Thairat Wittaya 75 School.

3) Education service area office region 3: Khosit Samosorn School, Wat Jaomool School, Taweeta Pisek Primary School, Wat Sangkrajai School, Ratchavinit Bangkae Primary School, Chang Lek School, Na Prok School. 


\section{Analysis}

Analysis of the qualitative data of external and internal environment survey and observation was done by a physical data presentation from involved computer systems. It included identifying the data from sample group's questionnaire and evaluating the data with the involved program.

\section{RESULTS}

Environment of the school buildings' managements for inclusive education between exceptional and normal children in 35 Bangkok schools are case-study that appeared to have a current state and general features. From survey and observation of the group of researchers, it can be summarized as follows:

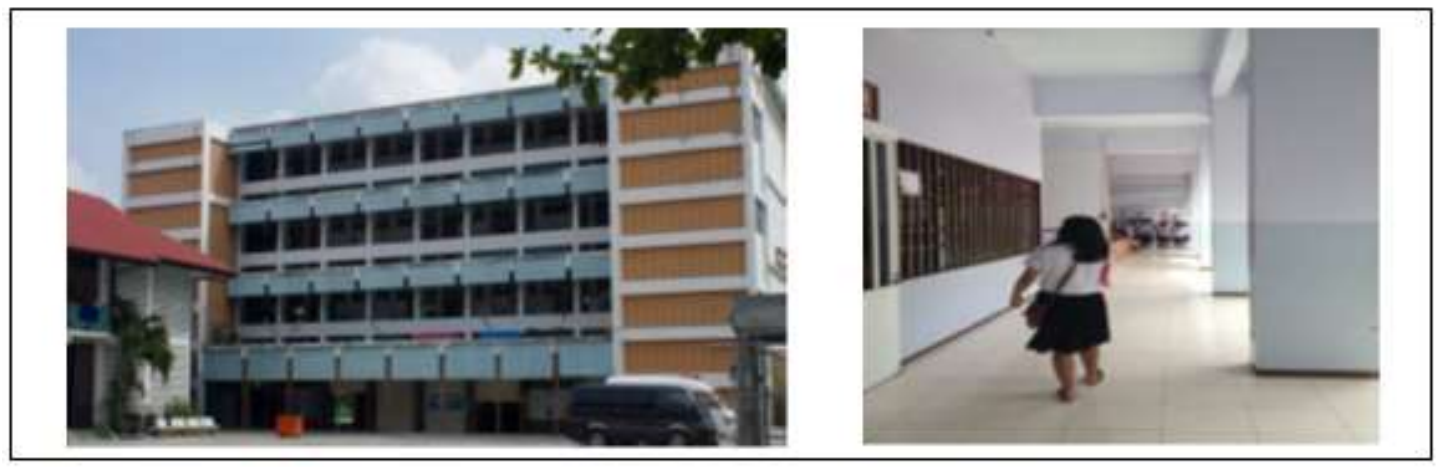

FIGURE 2. Showed the school buildings of Wat Nak Prok School in Pasri Chareon District

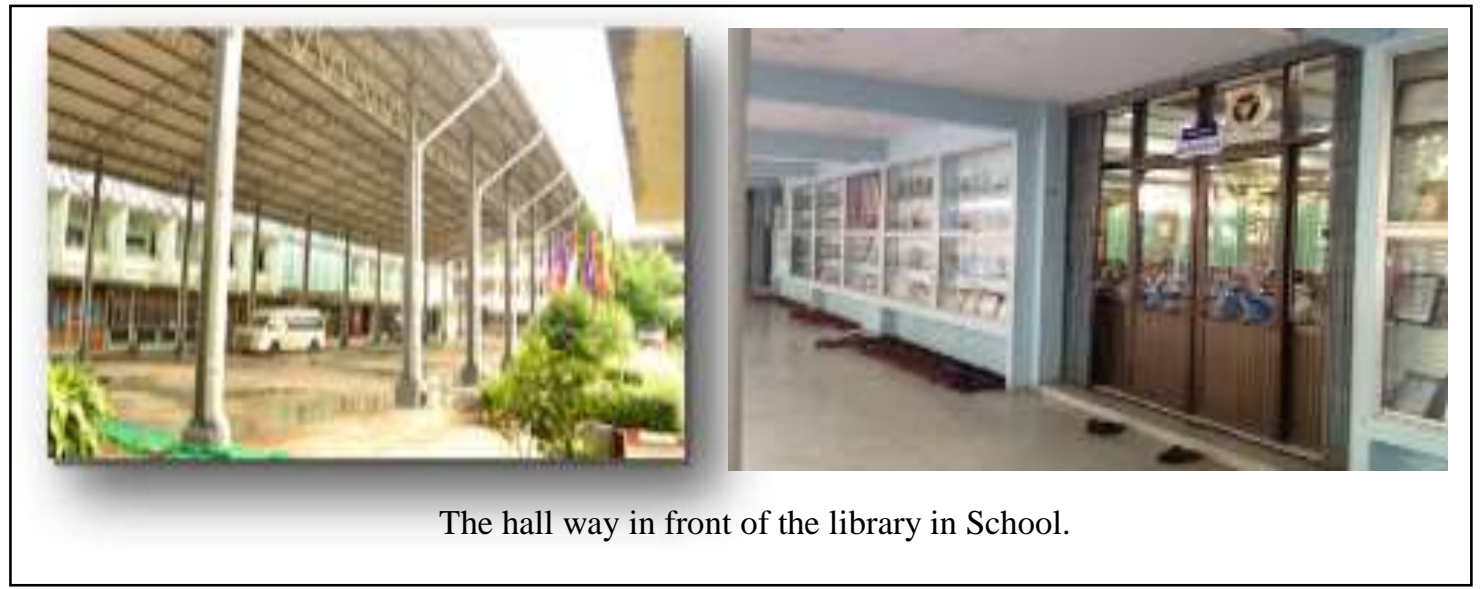

FIGURE 3. Showed hallways in Prathom Nonsee and Wat Amarintharam School

The hallways in Prathom Nonsee School were built both inside and outside the building. As per the survey and observation, the hallways are public area for many activities, and every special education school has at least one convenient standard-size hallway. In other words, the hallways were designed for protecting against noise pollution, but some areas have limitation of light and visual.

By the way, the library area in Wat Amarintharam School is a part of students' knowledge encouraging and academic research extension. However, most of the libraries are small and have small number of books, students do not use the library in their free-time. In other words, library area is used ineffectively. 


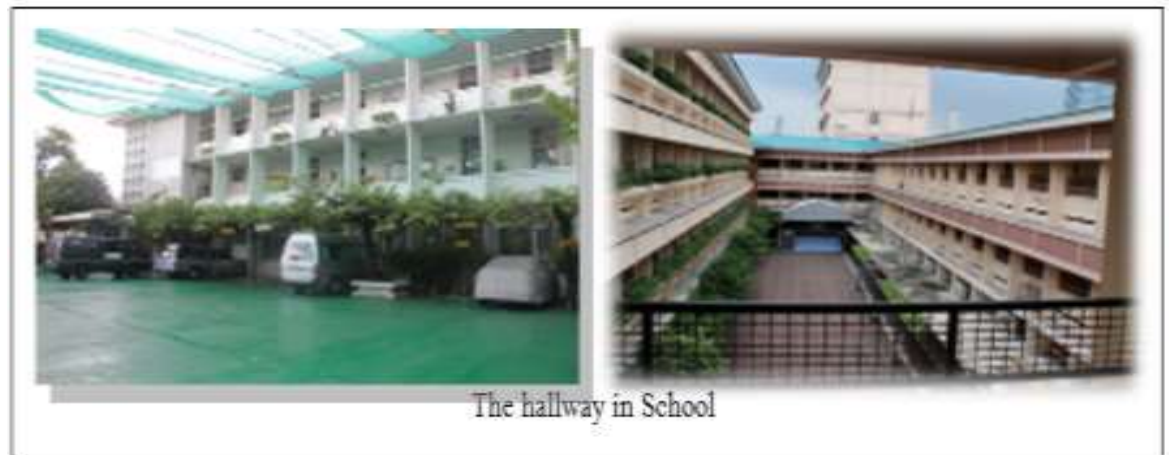

FIGURE 4. showed the activity exhibition halls of Plabpla Chai and Samsen primary School

TABLE 1. Showed the status and security in the school areas

\begin{tabular}{ccccccccccccc}
\hline \hline \multirow{2}{*}{ Status } & \multicolumn{10}{c}{ Security in the special education school-area } \\
\cline { 2 - 15 } & Highest & $\mathbf{\%}$ & High & $\mathbf{\%}$ & Moderate & $\mathbf{\%}$ & Low & $\mathbf{\%}$ & Lowest & $\mathbf{\%}$ & total & \% \\
\hline 1. Teachers & 3 & 4.9 & 4 & 6.6 & 10 & 16.4 & 28 & 45.9 & 16 & 26.2 & 61 & 100.0 \\
\hline 2. Staff & 3 & 14.3 & 0 & .0 & 2 & 9.5 & 11 & 52.4 & 5 & 23.8 & 21 & 100.0 \\
\hline 3. Students & 26 & 8.2 & 25 & 7.9 & 39 & 12.3 & 183 & 57.5 & 45 & 14.2 & 318 & 100.0 \\
\hline Total & 32 & 8.0 & 29 & 7.3 & 51 & 12.8 & 222 & 55.5 & 66 & 16.5 & 400 & 100.0 \\
\hline$\left(\mathrm{x}^{2}\right)$ & & & \multicolumn{10}{c}{ Sig. $=0.208, \mathrm{df}=8$} \\
\hline \hline
\end{tabular}

The results in the table 1 is a study of relationships between status of building-users and security of the school areas which was considered from Pearson Chi-Square value that indicated linear relationship and significant value calculation. Significance value (two-tailed) $=0.208$ means that security of the school areas is important to staff of teachers, staff and students. In other words, the results conformed to the learning of human beings, and the learning style; time period and environment are forced to make a using-area model and building improvement.

\section{DISCUSSION}

The researchers have summarized that the school building's environmental model which is appropriate with local areas is made to determine the policy of school building's environmental management for the inclusive education between exceptional and normal children in Regional Centre for Special Education. Thus, it leads to discussion as follows:

1. School building's environment for the inclusive education between exceptional and normal children in Regional Centre for Special Education.

Green-space in the special education schools are designed to be a physical and mental environment. The spaces are consistent with Wallapa Thephasadin $\mathrm{Na}$ Ayutthaya's concept of adaptation to the culture site. She talked about a relationship between human and physical environment, and a behavior process will be shown in Figure 5.

The football and sport outdoor field of Plabpla Chai School are a healthiness area of both students and staff. Also, all the universities and communities have a sport outdoor field and activities, but some locations are dilapidated and 
crowded because of area limitation. On the other hand, Samsen Primary School promoting education and social activity was significant to make a good relationship with universities and communities. Moreover, many activities will be provided at the special education schools and it will continually give its share to communities (Division of Education for the Disabled, 2000). By the way, some schools have area and resource limitation, so they are promoting some areas where they can manage to be a public area only.

From the survey, observation and field data collecting by questionnaires in a current state of the school buildings and security, the sample group which are teachers, professors, staff and students commented that the security school is a medium special education school at 55 percent of the collected data. The collected data will be shown in the table 1 .

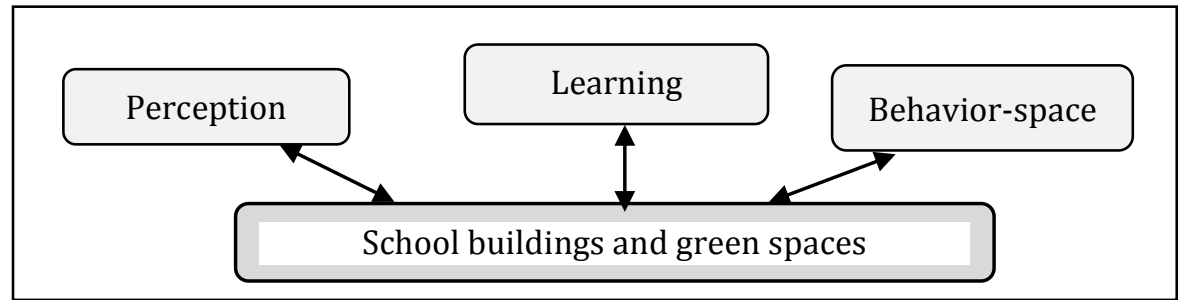

Figure 5. Showed school buildings and green spaces

The Figure 5 showed the school buildings and green-space in the special education schools which are designed to extend the learning process. Moreover, they lead to behavior-space by followed learning environmental improvement in universities.

2. The school building's environmental model for the inclusive education between exceptional and normal children which is appropriate with local areas. A main building-user is significant to building maintenance which is promoted by the concept of the school building's environment (Charungsirawatana, 2006). He talked about an appropriate environmental management for students' learning. The management promoted the teachers' potentiality in working and accommodated the students' improvement both in external and internal atmospheres. However, the status of the main building users is related to working time, and there are noise factors that play as a behavior determiner affected by the environment.

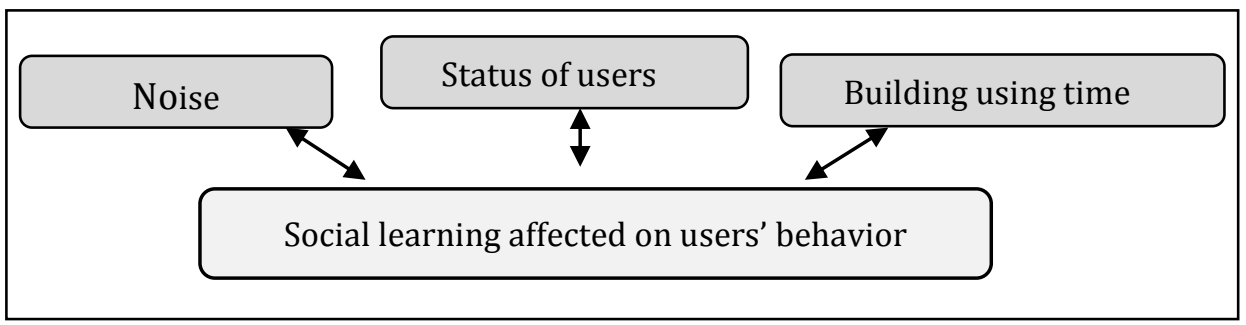

FIGURE 6. Showed the environment affected on the users

The Figure 6 showed that the environment affected on the behavior of building-users in the inclusive education schools. There are environmental factors of the building-users which are time and noise affected on the school building's environment directly. 
3. The policy determination for the inclusive education between exceptional and normal children. Currently, the environments are responded throughout an educational reaction by the main-users who are teachers, staff and students. By the way, each academy will do maintenance in a necessary-state. Moreover, the main-user whose number always changes and increases by year to year is students, so the adaptation of environmental direction depends on a change of users and buildings. Also, it related to the concept of educational facility and building planning (Pilanthananin, 1985). He described that the environment affected human adjustment, but humans have abilities which affect upon a circuit of the relationship to design the building to meet the environment.

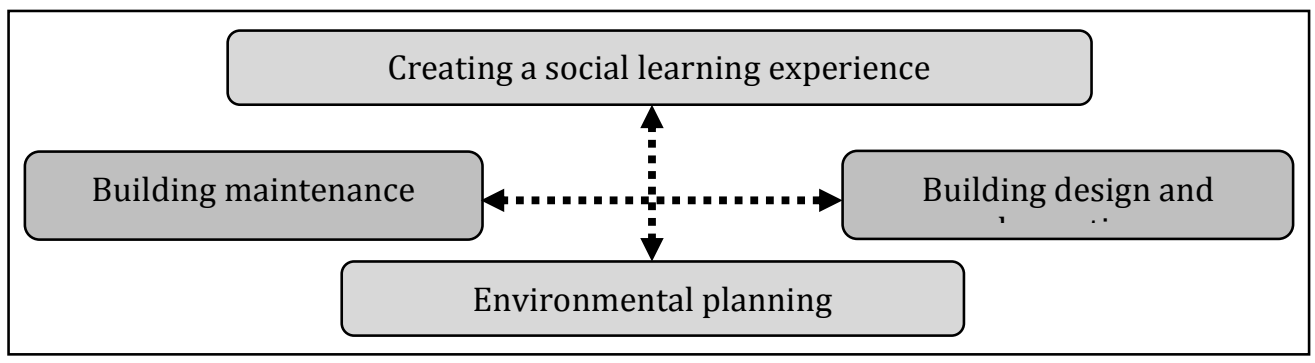

FIGURE 7. Showed environmental planning in the inclusive education schools

Figure 7 showed environmental planning that related to the building, design and decoration maintenance in the inclusive education schools, for determining a building improvement direction (Thipayasothorn, 2008). She described about an integration of physical environment from an architecture form, interior decoration and design durable articles. Moreover, the school buildings need to improve the social and user features for guideline of determination development. By the way, a mixed-ability classroom has students who have different skills at the same time, so the learning process depends on a significant concept that;

1. Strengthening learning interaction.

2. Learning management full of potentiality.

3. Forming students' groups who are willing for acquiring skill and development.

4. Creating experiences for self-learning and others.

However, classroom environmental processes which accommodate the learning process are two significant elements; a classroom environment and learning atmosphere.

\section{CONCLUSION AND RECOMMENDATIONS}

The direction of the environmental management for the inclusive education between exceptional and normal children from the study of the current spaces based on teaching activities in the school-building, the relationship between the space and social learning promotion affected by the space determination in creating social learning experience. Included is the experience related to the users' participation in the design and decoration of school-building. In other words, all the factors affected the space determination in the school buildings and created experience in social learning. As a recommendation of the outdoor 
area in Prathom Nonsee School, the thoroughfare should be clearly separated into 2 ways; people way and vehicles way as in Figure 8.

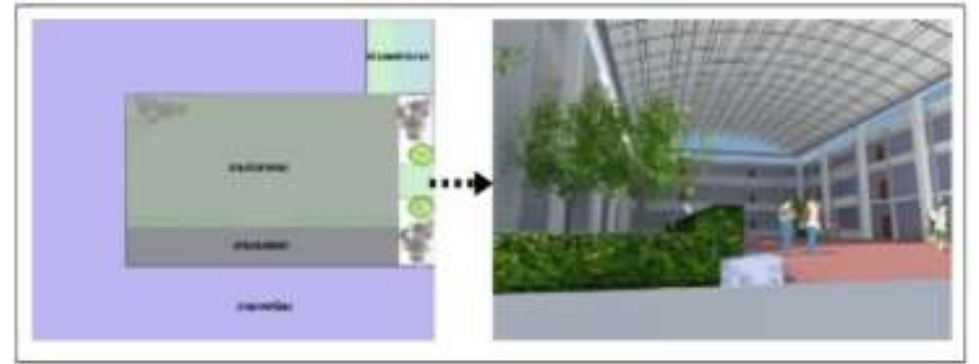

Figure 8. Showed the guideline of traffic flow in Prathom Nonsee School

The environmental development for the inclusive education between exceptional and normal children affected the guideline of atmosphere process in learning promotion. The learning promotion has space determined by integrating learning from physical architecture shape, interior design and design durable articles. Included are the school buildings that need to improve the social and users' features for determining the guidelines of development as the activity exhibition hall development recommendation at Plabpla Chai School (Figure 9).

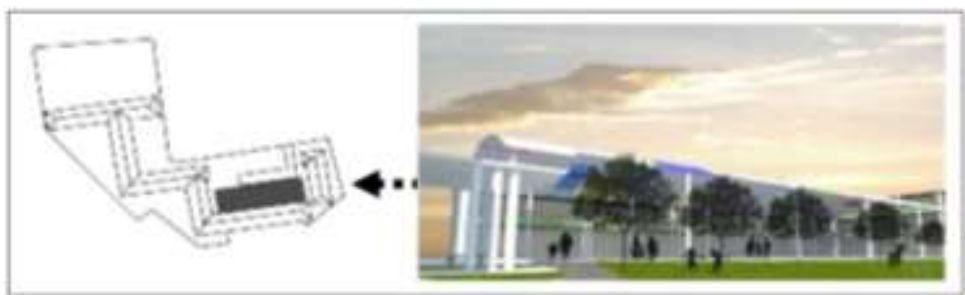

FIGURE 9. Showed the activity exhibition hall development recommendation at Plabpla Chai School

From the guidelines of the activity exhibition hall development at Plabpla Chai School in Figure 9, it showed that the design of the permanent roof in a round shape was used for covering from the sun and rain. Moreover, the symbol that was used for demarcating the parking zone was trees. Also, the trees help to increase the green zone and circulate the air to be fresh.

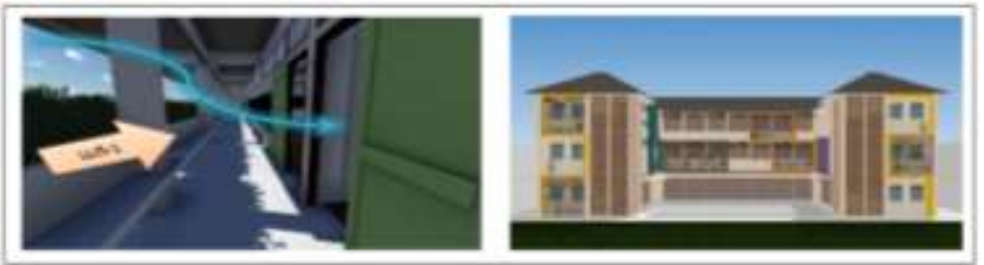

Figure 10. Showed the guideline of the heat reduction from the sunlight

Figure 10 showed the heat reduction from the sunlight when the reflective light leads the heat to the classroom. Also, creating the green roof helps to reduce the heat, but the light can pass and the wind can flow to the classroom by adding humidity of the wind. Awareness of school building's environmental maintenance, teaching's activity design and decoration and the school building's 
public relation are results from the researches of the inclusive education school's spaces for leading to behavior-space improvement.

\section{ACKNOWLEDGMENT}

The researchers really thank for corporation of educational area survey, questionnaire responding and information providing by the teachers, staff and students of 35 primary schools in Bangkok. Also, the group of third year students from Division of Architectural Education and Design, King Monkut's Institute of Technology Ladkrabang.

*This article is a part of the inclusive education between exceptional and normal children in Thailand Regional Centre for Special Education.

\section{REFERENCES}

Chanrungrueng, Nisan. 1998. Landscape improvement design for the garden behind the building of crop production technology department. Dissertation, King Mongkut's Institute of Technology Ladkrabang, Bangkok, TH.

Charungsirawatana, Ruangchai. 2006. The guideline of building utilization analysis (practical and example). Dissertation, Khon Kaen University, Khon Kaen, TH.

Chumnui, Ekkasit. 2004. Minprasatwitaya school's idea of environmental management of inclusive education for exceptional and normal students. Dissertation, King Mongkut's Institute of Technology Ladkrabang, Bangkok, TH.

Devahasdin De Ayutthaya, Wallapa. 1987. Higher education. Dissertation, Chulalongkorn University, Bangkok, TH.

Department of General Education Elementary and Adult Education Department. 1997. Inclusive educational instruction. Special Education Development Group, Bangkok, TH.

Division of Education for the Disabled. 2000. Information of division of education for the disabled's school. Bangkok: TH.

Pilanthananin, Methee. 1985. Educational buildings and facilities plan. Dissertation.

Pimolyanon, Kongrit. 2002. Elementary classroom design for natural comfort. Dissertation, King Mongkut's Institute of Technology Ladkrabang, Bangkok, TH.

Srisuwan, Malinee. 1999. Knowledge about the design of different types of public buildings. Dissertation, Silpakorn University, Bangkok, TH.

Techakitkajorn, Komsan. 1997. Guideline of electricity energy saving. Dissertation, King Mongkut's Institute of Technology Ladkrabang, Bbangkok, TH.

Thipayasothorn, Pastraporn. 2008. Integrating the physical environment of architectural form, interior design and school building for promoting industrial education's graduate production. Dissertation, King Mongkut's Institute of Technology Ladkrabang, Bngkok, TH.

Waitoller, Federico R., and Alfredo J. Artiles. 2013. A decade of professional development research for inclusive education: A critical review and notes for a research program. Review of educational research 83, no. 3: 319-356.

Yildiz, Nevin Guner. 2015. Teacher and Student Behaviors in Inclusive Classrooms. Educational Sciences: Theory and Practice 15, no. 1: 177-184.

— This article does not have any appendix. - 